\title{
Pemanfaatan Autotransformator Sebagai Pengontrol Arus Start Motor Induksi Tipe LH 73204 Guna Menjaga Kestabilan Tegangan Listrik di Laboratorium Konversi Energi Teknik Elektro Universitas Udayana
}

\author{
I Wayan Lastera ${ }^{1}$ \\ [Submission: 25-03-2019, Accepted: 22-06-2019]
}

\begin{abstract}
Practicum activities at the Energy Conversion Laboratory of Electrical Engineering Udayana University, using induction motors that operated directly connected to the power source, so that start current of the motor becomes large enough to cause electrical voltage stability to be disturbe. Conditions like these can damage other laboratory equipment. So that research using autotrasformator as a starting, the aims to produce a model of controlling the starting current on the operation of induction motor Type $\mathbf{L H 7 3 2 0 4}$. In research, the input voltage to the motor is gradually lowered from 220 Volts to 88 Volts with autotransformator at the start of the motor, then motor starting current is observed for each phase of the input voltage drop. Data were tabulated and analyzed descriptively, showed that the utilization autotransformator starting current operation induction motor type LH 73204 capable suppressed $44,11 \%$ or 3 Apere lower. so that becomes a model and test method for controlling the starting current induction motor. This model is very useful for maintaining electrical voltage stability, so that laboratory equipment works optimally.
\end{abstract}

Intisari-Kegiatan praktikum di Laboratorium Konversi Energi Teknik Elektro Universitas udayana, menggunakan motor-motor induksi yang dioperasikan secara langsung dihubungkan ke sumber tenaga, sehingga arus start motor menjadi cukup besar yang mengakibatkan kesetabilan tegangan listrik menjadi terganggu. Kondisi seperti ini dapat merusak peralatan laboratorium yang lain. Sehingga dilakukanlah penelitian memanfaatkan autoranformator sebagai starting, tujuannya untuk menghasilkan model pengontrolan arus starting pada pengoperasian motor induksi Tipe LH73204. Pada penelitian, tegangan input ke motor diturunkan bertahap mulai 220 Volt sampai 88 Volt dengan autotransformator pada saat proses starting motor tersebut, kemudian dilakukan pengamatan arus start motor untuk setiap tahap penurunan tegangan input tersebut. Data yang diperoleh ditabulasi dan dianalisa secara deskriptif, didapatkan hasil bahwa dengan pemanfaatan autotransformator arus start pengoperasian motor induksi tipe LH 73204 mampu ditekan 44,11\% atau 3 Amper lebih rendah. Sehingga menjadi model dan metode pengujian untuk pengontrolan arus starting motor induksi. Model ini sangat berguna untuk menjaga kesetabilan tegangan listrik, sehingga kerja peralatan laboratorium menjadi optimal.

Kata Kunci- autotransformator, arus start, kestabilan tegangan.

\section{PENDAHULUAN}

${ }^{1}$ PLP Muda, Program Studi Teknik Elektro Fakultas Teknik Universitas Udayana, Jln. Kampus Bukit Jimbaran 80361 INDONESIA (telp: 0361-703315; fax: 0361-432103315; e-mail: wayan.lastera@unud..ac.id

I Wayan Lastera: Pemanfaatan Autotransformator sebagai pengontrol.......
Praktikum di Laboratorium Konversi Energi Teknik Elektro Universitas Udayana, menggunakan motor-motor listrik dengan jenis motor induksi yang dioperasikan secara langsung dihubungkan ke sumber tenaga listrik yang tersedia di laboratorium. Motor induksi yang dioperasikan secara langsung dihubungkan ke sumber tenaga listrik, akan menarik arus yang cukup besar sehingga mengakibatkan terjadinya

kestabilan tegangan listrik menjadi terganggu, akan mempengaruhi kinerja peralatan laboratorium jika dibiarkan berlangsung terus-menerus.

Mengingat kegiatan praktikum yang cukup padat di laboratorium, maka perlu dilakukan penelitian yang bisa mengatasi dampak buruk yang mungkin terjadi. Penelitian pemanfaatan autotransformator pada pengoperasian motor induksi tipe LH 73204, diupayakan mampu mengatasi permasalahan tegangan dilaboratorium. Sehingga peralatan laboratorium bekerja optimal.

\section{MOTOR INDUKSI}

\section{A. Pengertian Motor Induksi}

Motor induksi adalah merupakan motor arus bolak-balik yang bekerja berdasarkan prinsip induksi elektromagnetik.

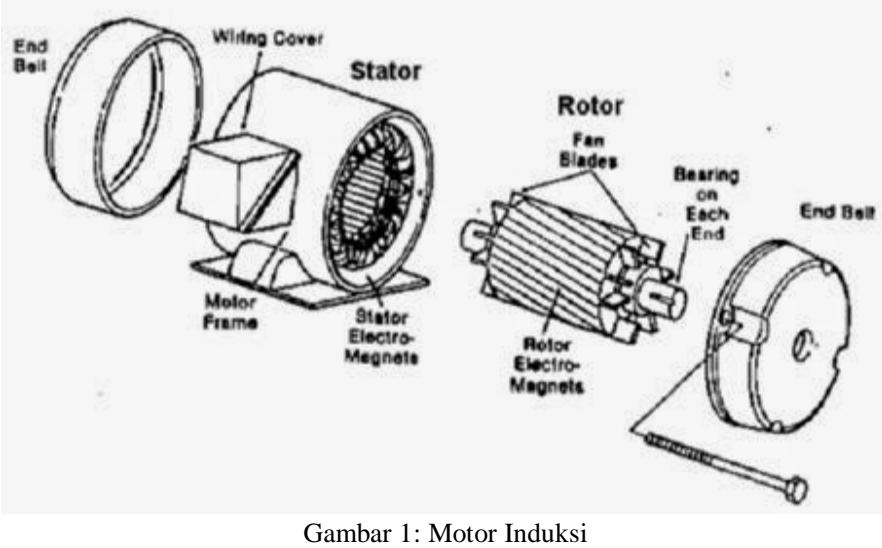

Pada motor induksi, rotor menerima energi listrik dari stator secara induksi [1]. Jika sumber listrik di hubungkan ke stator, maka pada kumparan tersebut timbul medan putar stator yang berbanding lurus dengan frekwensi dan berbanding terbalik dengan jumlah kutub pada stator motor induksi. [2]. Medan putar ini memotong batang-batang konduktor dari kumparan rotor yang mengakibatkan timbul gaya listrik induksi yang menyebabkan motor induksi mulai start. Tegangan induksi p-ISSN:1693 - 2951; e-ISSN: 2503-2372 
saat star, berbanding lurus dengan frekwensi sumber listrik, jumlah belitan pada rotor dan fluk putar maksimum yang muncul di rotor. Pada motor induksi rotor sangkar, kumparan rotor merupakan rangkaian tertutup, sehingga dengan adanya gaya gerak listrik (ggl) induksi rotor (Er) akan menghasilkan arus rotor (Ir). Dengan adanya Ir pada medan magnet putar, maka pada rotor timbul gaya Lorentz $(\mathrm{F})$ yang besarnya berbanding lurus dengan nilai perkalian antara kerapatan fluks, panjang kumparan rotor dan kuat arus yang mengalir di kumparan rotor. [3]. Momen putar yang muncul di rotor besarnya akan berbanding lurus dengan besarnya gaya Lorentz dirotor dan jari-jari rotor.

Bila kopel awal rotor yang dihasilkan oleh gaya Lorentz di rotor cukup besar untuk mengatasi kopel beban, rotor akan berputar searah dengan medan putar stator. Adapun besar ggl kumparan rotor saat rotor sedang berputar adalah berbanding lurus dengan frekwensi rotor, putaran rotor, fluks maximum rotor dan slip.[4]. Untuk motor induksi 1 phase sebenarnya tidak mempunyai torsi awal saat dihidupkan, tetapi bila kumparan stator dieksitasi dan rotor diputar dengan alat pembantu start, konduktor rotor akan memotong medan stator dan menyebabkan dibangkitkannya ggl pada rotor tersebut sehingga rotor berputar. [5]. Alat pembantu start motor induksi 1 phase adalah kapasitor, dimana dengan kapasitor mampu memisahkan phase arus rotor terhadap arus stator sebesar $90^{\circ}$ listrik, sehingga dinamakan jenis motor kapasitor.

\section{B. Autotransformator}

Seperti ditunjukkan pada gambar 2 autotransformator kontruksinya sedikit berbeda dengan transformator biasa, dimana belitan primer dan belitan sekunder menjadi satu belitan. [6]. Belitan primer dihubungkan dengan Sumber tegangan jala-jala, sedangkan belitan sekunder dibungkan dengan beban. Dalam melakukan perhitungan besaran-besaran dari transformator ini berlaku persamaan perbandingan tegangan primer dengan tegangan sekunder, nilainya sama dengan nilai perbandingan antara belitan primer dengan belitan sekunder dan nilainya sama dengan nilai perbandingan arus sekunder dengan arus primer. [7].

Gambar 2 adalah autotransformator:

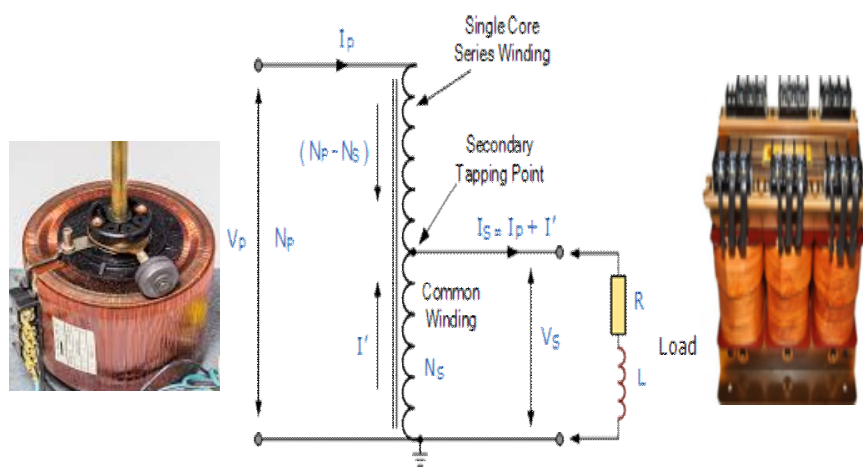

Gambar 2: Autotransformator

Penggunaan autotransformator membantu dalam pengasutan motor listrik, karena pengasutan dengan model ini cukup sederhana dimana tegangan awal yang masuk ke terminal motor diturunkan beberapa saat pada saat start sampai motor listrik mencapai kecepatan normalnya, kemudian tegangan motor dikembalikan ke tegangan normal.[8]. Dengan metode ini arus start pada motor menjadi berkurang sehingga drop tegangan jaringan menjadi kecil. [9]. Arus starting yang rendah membuat kesetabilan sumber tenaga lebih terjaga. Kerja peralatan laboratorium menjadi lebih optimal. Arus starting yang besar berpotensi membuat kesetabilan sumber tenaga terganggu, yang bisa mengakibatkan kerja alat laboratorium tidak optimal bahkan mengalami kerusakan.[10].

\section{METODE}

Penelitian dilakukan bertahap, ditunjukkan pada gambar 3 . Data awal diambil dari name plate motor induksi tipe $\mathrm{LH}$ 73204 , daya motor $=0.3 \mathrm{KW}$, tegangan $=220 \mathrm{~V}$, arus $=2 \mathrm{~A}$, factor daya $=0.97$, frekuensi $=50 \mathrm{~Hz}$, kecepatan motor $=2850$ $\min ^{-1} . \mathrm{CB}=10 \mu \mathrm{F}$. Untuk melengkapi data yang diperlukan diambil dari hasil pengujian.

Gambar 3, menunjukkan alur dari penelitian:

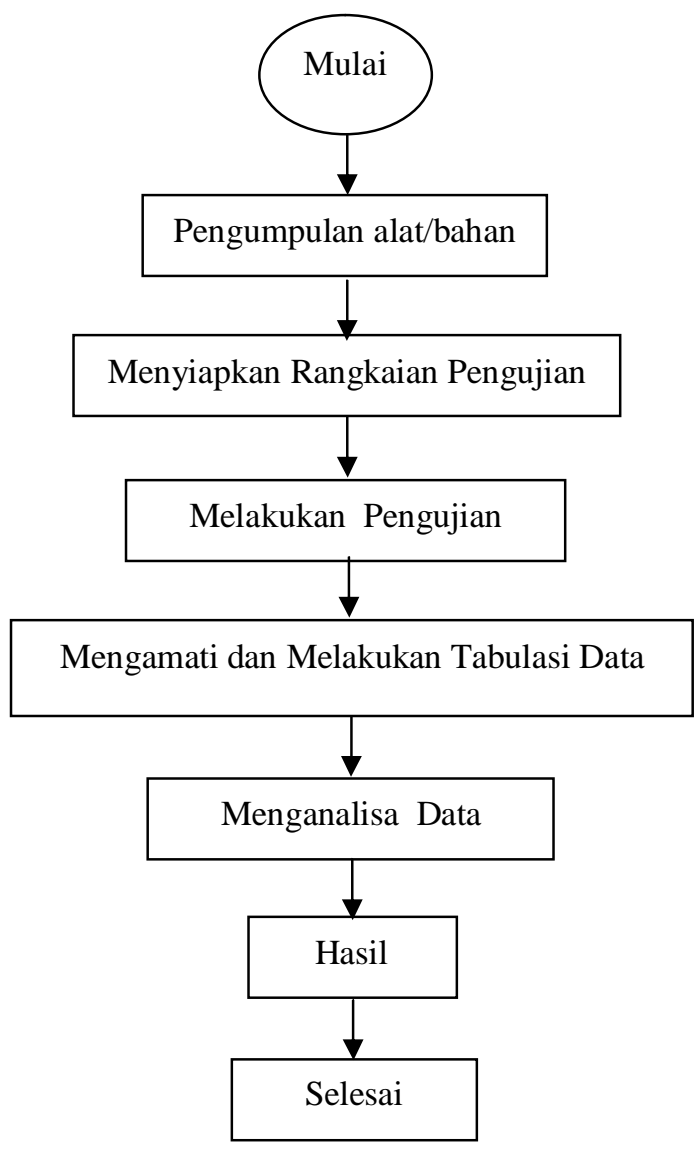

Gambar 3: Flowcart penelitian

Pelaksanaan penelitian, mengikuti gambar 3:

1.Penelitian dimulai dengan menyiapkan mental, administrasi pendukung penelitian, literature, dan tempat.

2.Pengumpulan alat dan bahan yang digunakan: Motor induksi tipe LH73204, alat ukur amper meter, Volt meter, Power meter, Tacho meter, Autotransformator, Fuse, Panel Sumber Daya. Dilakukan pengecekan kinerja alat dan dipastikan alat dalam kondisi baik. Bahan-bahan yang digunakan kabel jumper, pelumas, bolpoin, buku tulis, disiapkan seperlunya. 
3.Menyiapkan rangkaian pengujian, melakukan pengawatan yang diperlukan pada saat pengambilan data pengujian mengikuti gambar 4:

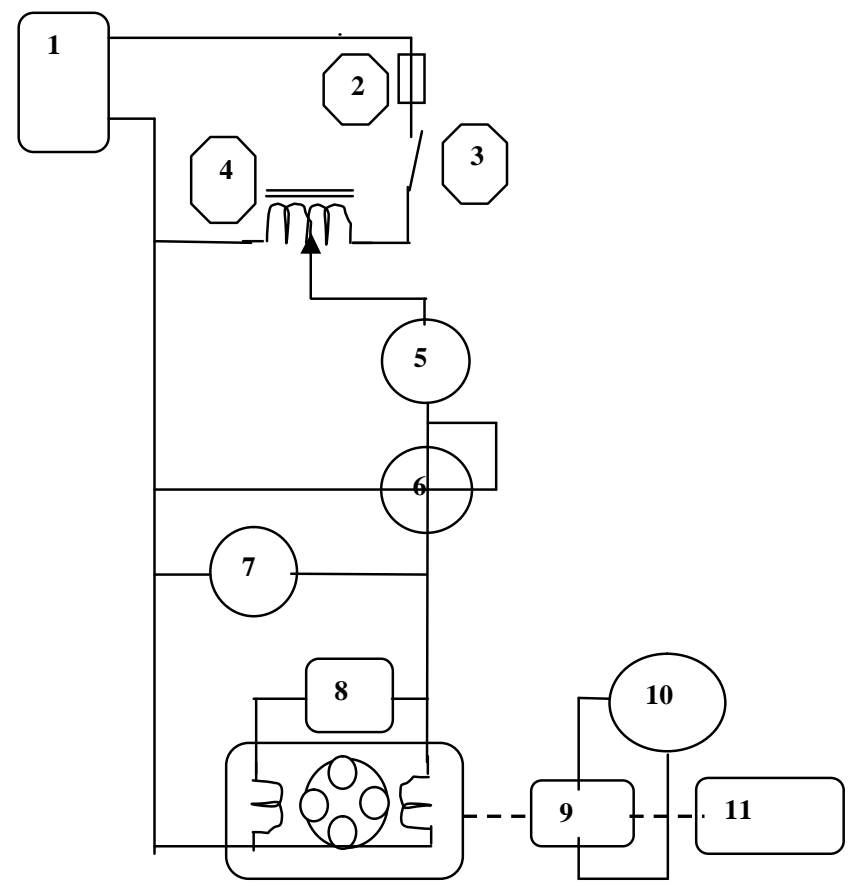

Keterangan :

1. Sumber tenaga listrik 1 phase

2. Pengaman.

3. Saklar.

4. Autotransformator.

5. Amper meter.

6. Power meter.

7. Volt meter.

8. Motor induksi 1 phase starting kapasitor.

9. Tacho generator.

10. Tacho meter

11.Magnetic power brake.

Gambar 4: Rangkaian pengoperasian motor induksi 1 phase tipe LH 73204 dengan menggunakan autotransformator

\section{Melakukan pengujian}

Untuk pengoperasian motor induksi 1 phase tipe LH 73204 dengan menggunakan autotransformator, mengikuti gambar 4, diawali dengan memastikan seting autotransformator pada posisi $100 \%$ dari tegangan input trafo atau tegangan 220 Volt, kemudian on-kan saklar 3 maka motor mulai beroperasi (starting), amati dan catatlah arus start motor (Ist), arus raning (Ir) dengan menggunakan amper meter, dan catatlah tegangan input (Vin) motor dengan volt meter, daya starting motor (Pst), daya raning motor (Pr) dengan power meter, waktu untuk mencapai raning $(\mathrm{T})$ dengan stop watch, putaran motor/menit (Rpm) dengan tacho meter. Kemudian hentikan pengoperasian motor, lakukan dengan menekan saklar 3 keposisi OFF, sehingga arus listrik terputus ke motor dan motor berhenti. Seting kembali autotransformator pada posisi $95 \%$ dari tegangan input trafo atau tegangan 209 Volt, kemudian onkan saklar 3 maka motor mulai beroperasi (starting), amati I Wayan Lastera: Pemanfaatan Autotransformator sebagai pengontrol....... dan catatlah arus start motor (Ist), arus raning (Ir) dengan menggunakan amper meter, dan catatlah tegangan input (Vin) motor dengan volt meter, daya starting motor (Pst), daya raning motor (Pr) dengan power meter, waktu untuk mencapai raning $(\mathrm{T})$ dengan stop watch, putaran motor/menit (Rpm) dengan tacho meter.

Kemudian hentikan pengoperasian motor, lakukan dengan menekan saklar 3 keposisi OFF, sehingga arus listrik terputus ke motor dan motor berhenti.

Ulangi langkah 4 untuk posisi autotransformator $90 \%, 85 \%$ dst, mengikuti tabel 1, Sampai diperoleh data yang lengkap. Pengujian dihentikan sampai motor tidak mampu starting, dengan adanya penurunan tegangan input ke motor.

5.Melakukan tabulasi data.

Data dimasukkan ke dalam tabel, pada tabel I untuk data Vin Motor dan tabel II untuk data pengujian pengoperasian motor dengan autotransformator.

\section{HASIL DAN PEMBAHASAN}

Pengujian pengoperasian motor induksi 1 phase tipe LH 73204 dengan menggunakan autotransformator, dilakukan bertahap mulai dari tegangan nominal motor, kemudian tegangan input motor diturunkan sampai tegangan paling rendah untuk motor masih bisa berputar. Seperti yang ditunjukkan pada gambar 5 dan gambar 6 (a,b,c,d):

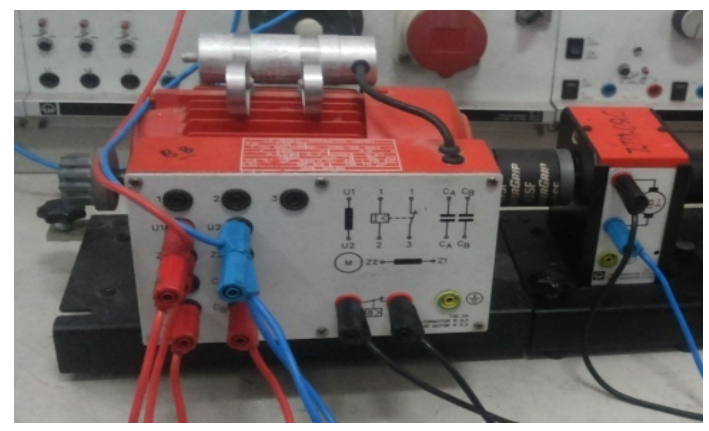

Gambar 5. Motor induksi 1 phase type LH 73204
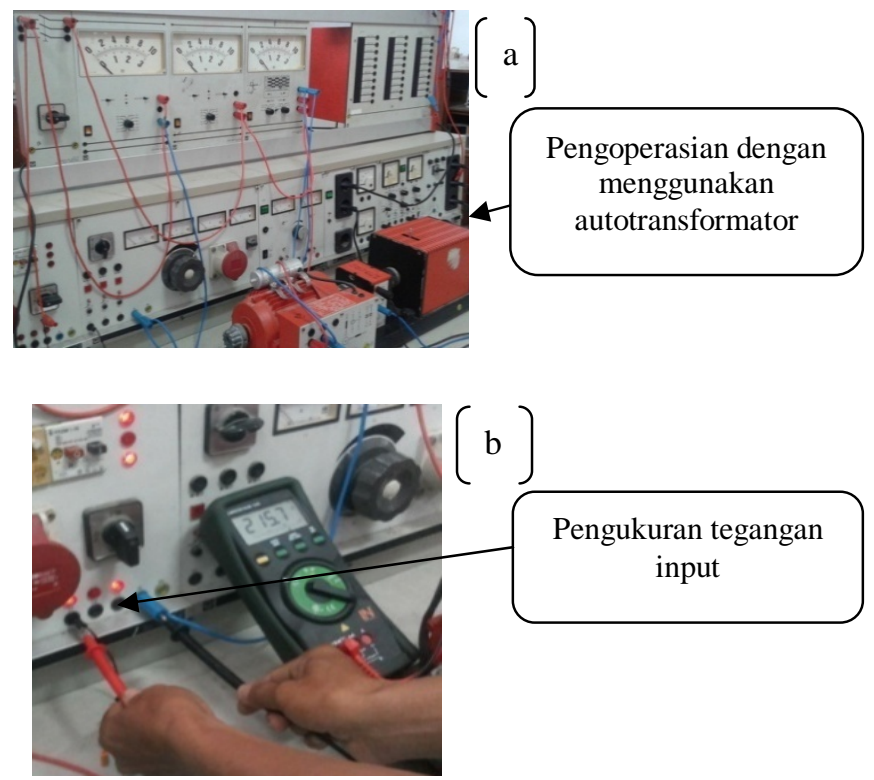

p-ISSN:1693 - 2951; e-ISSN: 2503-2372 

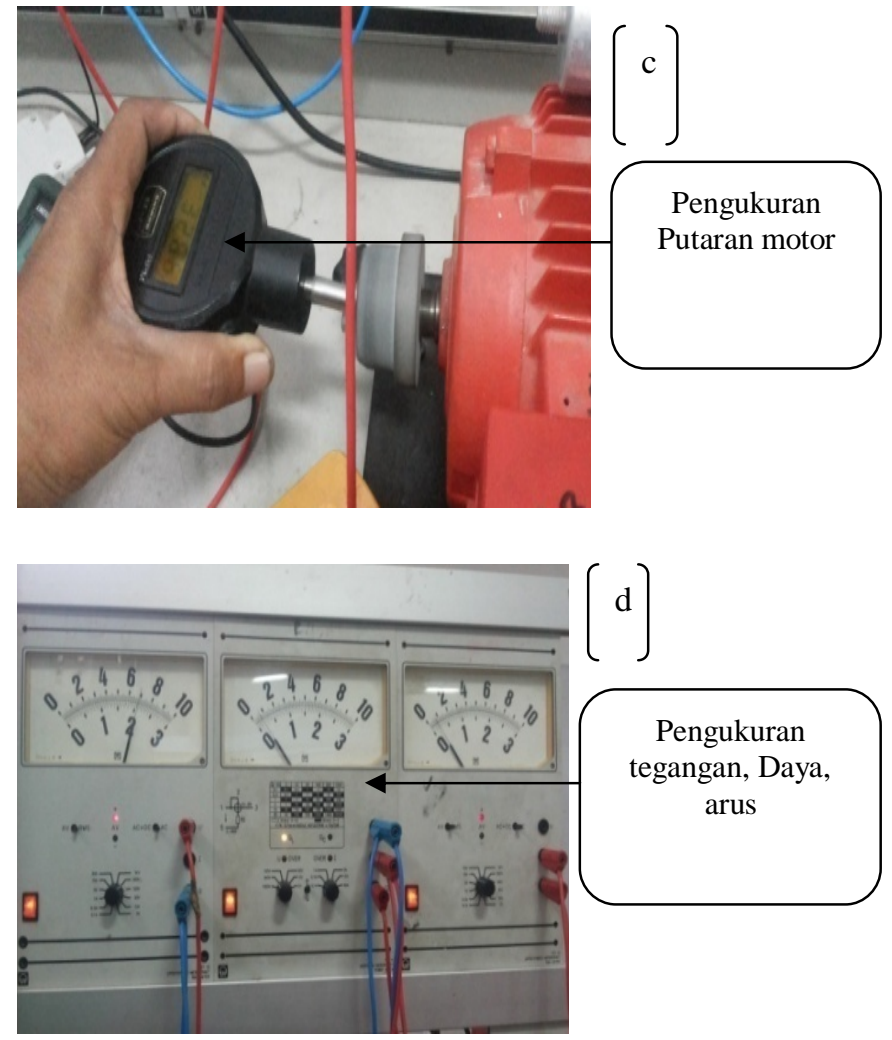

$(d)$

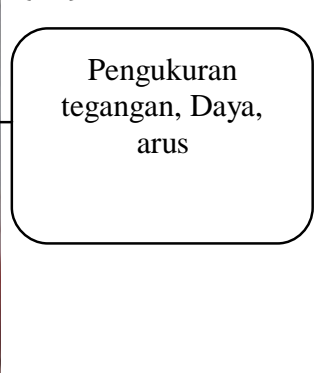

Gambar 6: (a,b,c,d) Pengujian pengoperasian motor induksi 1 phase tipe LH 73204 dengan menggunakan autotransformator

Dari gambar pengujian dapat dijelaskan sebagai berikut:

Gambar 5 menunjukkan motor induksi 1 phase tipe LH 73204. Gambar 6(a) menunjukkan pengoperasian motor induksi 1 phase tipe LH 73204 dengan menggunakan autotransformator. Motor tidak langsung menyerap arus litrik dari jala-jala, arus yang diserap motor melewati autoransformator. Gambar 6(b) i menunjukkan pengukuran tegangan input ke motor. Pengukuran putaran ditunjukkan pada gambar 6(c), pengukuran tegangan, daya dan arus ditunjukkan pada gambar 6(d). Data pengujian yang telah dimasukkan ke dalam tabel, ditunjukkan pada tabel I dan tabel II:

TABEL I

DATA V IN MOTOR

\begin{tabular}{|c|c|c|c|c|c|c|}
\hline \multicolumn{7}{|c|}{ Vin autotransformator $=220$ Volt } \\
\hline \multicolumn{6}{|c|}{ Vout autotransformator atau Vin motor $=$ Volt } \\
\hline $40 \%$ & $45 \%$ & $50 \%$ & $55 \%$ & $60 \%$ & $65 \%$ & \\
\hline 88 & 99 & 110 & 121 & 132 & 143 & \\
\hline $70 \%$ & $75 \%$ & $80 \%$ & $85 \%$ & $90 \%$ & $95 \%$ & $100 \%$ \\
\hline 154 & 165 & 176 & 187 & 198 & 209 & 220 \\
\hline
\end{tabular}

Prosentase pada tabel I menunjukkan perbandingan tegangan output autotransformator dengan tegangan inputnya dikalikan $100 \%$. Perhitungan ini untuk memudahkan melakukan penurunan bertahap pada tegangan input motor, sehingga bisa didapatkan parameter yang ditunjukkan pada tabel II.
TABEL II.

DATA PENGUJIAN PENGOPERASIAN MOTOR INDUKSI 1 PHASE TIPE LH 73204 DENGAN MENGGUNAKAN AUTOTRANSFORMATOR

\begin{tabular}{|c|c|c|c|c|c|c|c|}
\hline $\begin{array}{c}\text { Vin } \\
\text { Volt }\end{array}$ & Ist Max Amper & $\begin{array}{c}\text { Pst } \\
\text { watt }\end{array}$ & $\begin{array}{c}\text { Ir } \\
\text { Amper }\end{array}$ & $\begin{array}{c}\text { Pr } \\
\text { watt }\end{array}$ & $\begin{array}{c}\text { T } \\
\text { detik }\end{array}$ & $\begin{array}{c}\text { Nr } \\
\text { RPM }\end{array}$ & Ket \\
\hline 220 & 6.8 & 1335 & 0.80 & 200 & 1.63 & 2973 & AT1 \\
\hline 209 & 6.7 & 1300 & 0.80 & 200 & 1.64 & 2959 & AT2 \\
\hline 198 & 6.5 & 1250 & 0.80 & 200 & 1.84 & 2957 & AT3 \\
\hline 187 & 6.4 & 1200 & 0.80 & 200 & 1.90 & 2959 & AT4 \\
\hline 176 & 6.3 & 1100 & 0.80 & 200 & 1.92 & 2954 & AT5 \\
\hline 165 & 6.2 & 950 & 0.80 & 200 & 1.96 & 2945 & AT6 \\
\hline 154 & 6 & 900 & 0.80 & 200 & 2.01 & 2954 & AT7 \\
\hline 143 & 5.6 & 750 & 0.80 & 200 & 2.38 & 2945 & AT8 \\
\hline 132 & 5.2 & 650 & 0.80 & 200 & 2.57 & 2950 & AT9 \\
\hline 121 & 4.7 & 550 & 0.80 & 200 & 2.93 & 2954 & AT10 \\
\hline 110 & 4 & 400 & 0.80 & 200 & 3.60 & 2954 & AT11 \\
\hline 99 & 3.8 & 280 & 0.80 & 200 & 5.71 & 2954 & AT12 \\
\hline 88 & 3.2 & 230 & 0.80 & 200 & $>6$ & 0 & AT13 \\
\hline
\end{tabular}

Keterangan:

AT1-13 adalah tahapan pengoperasian dengan menggunakan autotransformator.

Pada tabel I ditunjukkan data tegangan masukan (Vin) motor. Besar tegangan masukan (Vin) autotransformator $220 \mathrm{~V}$, tegangan keluarannya (Vout) untuk prosentase $100 \%$ dari tegangan $220 \mathrm{~V}$ diperoleh $220 \mathrm{~V}$. Untuk prosentase $95 \%$ dari $220 \mathrm{~V}$ diperoleh $209 \mathrm{~V}$, dan seterusnya sampai prosentase $40 \%$. Nilainya bisa dilihat di tabel I. Pengaturan tegangan ini dilakukan sebagai sampling tegangan masukan (Vin) motor yang diuji, sehingga didapat data yang diperlukan untuk pengujian selanjutnya.

Pada tabel II menunjukkan: tahap 1, data Vin besarnya 220 Volt, ini adalah tegangan input motor. Ist max besarnya 6,8 Amper, ini adalah arus start maximum. Pst besarnya 1335 watt, ini adalah daya motor pada saat start. Ir besarnya 0,80 Amper, ini adalah arus running (arus setelah motor berputar normal). Pr besarnya 200 watt, ini adalah daya running (daya setelah motor berputar normal). $\mathrm{T}$ besarnya 1,63 detik, ini adalah waktu yang dibutuhkan untuk start. Nr besarnya 2973, ini adalah putaran motor dalam RPM (repultion/ minute). Untuk tahap 2 dan seterusnya maknanya sama yang berbeda adalah besarannya. Dengan data pada tabel II, kita bisa mengetahui dengan penurunan tegangan bisa menurunkan arus start dan daya start. Arus running dan daya running hampir tidak berubah. Putaran rotor motor (Nr) tidak banyak perubahan. Waktu dari starting menuju running (T) bertambah. Data hasil pengujian juga ditampilkan dalam bentuk grafik ditunjukkan pada gambar 7 dan gambar 8 :

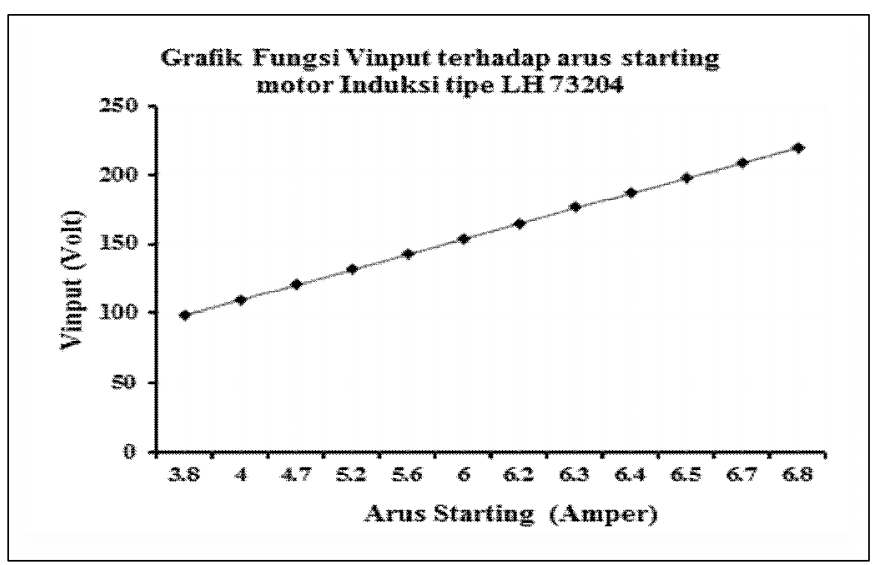

Gambar 7: Grafik fungsi Vinput terhadap arus start motor induksi tipe LH 73204 


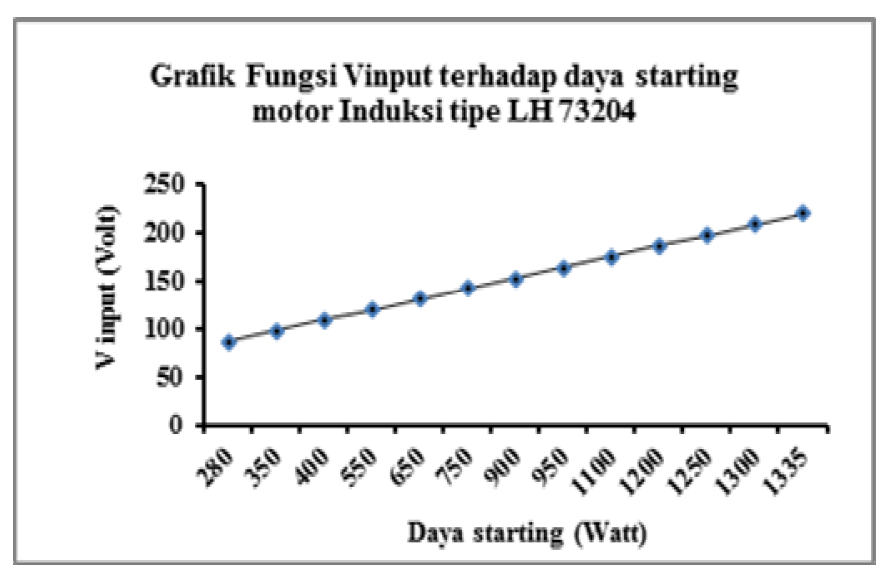

Gambar 8: Grafik fungsi Vinput terhadap daya start motor induksi tipe LH 73204

Gambar 7 menunjukkan dengan penurunan tegangan input ke motor, dibarengi dengan penurunan nilai arus starting (Ist). Titik terrendah pada grafik yang ditunjukkan gambar 7, kalau kita tarik garis lurus ke sumbu $\mathrm{Y}$ yang mewakili nilai tegangan masukan (Vin) motor, akan ketemu nilai 99 vol, yang merupakan tegangan masukan terrendah motor mampu berputar (start). Titik terrendah pada grafik, ditarik garis lurus kearah sumbu X yang mewakili nilai arus start motor, akan ketemu nilai 3,8 Amper, yang merupakan arus start terrendah motor mampu berputar (start).

Gambar 8 menunjukkan dengan penurunan tegangan input ke motor, dibarengi dengan penurunan nilai daya starting (Pst). Titik terrendah pada grafik yang ditunjukkan gambar 8 , kalau kita tarik garis lurus ke sumbu $\mathrm{Y}$ yang mewakili nilai tegangan masukan (Vin) motor, akan ketemu nilai 99 volt, yang merupakan tegangan masukan terrendah motor mampu berputar (start). Titik terrendah pada grafik, ditarik garis lurus kearah sumbu X yang mewakili nilai daya start motor, akan ketemu nilai 350 Watt, yang merupakan daya start terrendah motor mampu berputar (start).

Dari keseluruhan data pengujian yang diperoleh dan dari pengamatan visualisasi pada grafik terlihat pada tegangan 99 volt merupakan nilai tegangan terrendah untuk starting. Karena pada titik ini motor masih bisa berputar. Dibawah tegangan 99 Volt sudah tidak mampu berputar lagi. Ditunjukkan pada tahapan terakhir, tahap 13 ( AT 13) ditabel II Nr nilainya nol, artinya motor tidak berputar karena tidak cukup daya yang diperlukan motor untuk berputar.

Selisih nilai arus start motor induksi tipe LH 73204 yang diteliti, pada tegangan 220 Volt dengan tegangan 99 Volt, didapat selisih $(6,8 \mathrm{~A}-3,8 \mathrm{~A})=3 \mathrm{~A}$, ini artinya terjadi penurunan arus starting terbesar 3 Amper. Kalau diprosentasekan $((6.8 \mathrm{~A}-3.8 \mathrm{~A}) / 6.8 \mathrm{~A}) \times 100 \%=44.11 \%$.

Pemanfaatan autotransformator bisa dijadikan suatu model pengontrolan arus starting yang sangat berguna untuk menjaga kesetabilan tegangan pada saluran sumber tenaga. Terbukti dengan model ini, arus start lebih rendah dari pengoperasian secara langsung. Sehingga kerja peralatan laboratorium menjadi lebih optimal atau terbaik dan kerusakan bisa dikurangi. Arus starting yang besar berpotensi membuat kesetabilan sumber tenaga terganggu, bisa mengakibatkan kerja alat laboratorium tidak optimal bahkan mengalami I Wayan Lastera: Pemanfaatan Autotransformator sebagai pengontrol....... kerusakan. Ini terjadi sebelum dipasangkan autotrafo atau sebelum penelitian ini.

\section{KESIMPULAN}

Dari hasil dan pembahasan dapat disimpulkan:

Selisih nilai arus start motor induksi tipe LH 73204 yang diteliti pada tegangan input 220 Volt dengan tegangan input 99 Volt, didapat $(6,8 \mathrm{~A}-3,8 \mathrm{~A})=3 \mathrm{~A}$, ini artinya terjadi penurunan arus starting sebesar 3 Amper. Kalau diprosentasekan $((6.8 \mathrm{~A}-3.8 \mathrm{~A}) / 6.8 \mathrm{~A}) \times 100 \%=44.11 \%$.

Pemanfaatan autotransformator bisa dijadikan suatu model pengontrolan arus starting yang berguna untuk menjaga kesetabilan tegangan pada saluran sumber tenaga. Terbukti dengan model ini, arus start lebih rendah dari pengoperasian secara langsung. Sehingga kerja peralatan laboratorium menjadi lebih optimal atau terbaik dan kerusakan bisa dikurangi.

\section{REFERENSI}

[1] M.K. Shihab, I.M.A. Nrartha, and I.M.B. Suksmadana, Analisis Arus Starting dan Torsi Pada Motor Induksi Tiga Fasa Terhadap Pemasangan Kapasitor Secara Rreal Time Berbasis ATMEGA 2560. Dielektrika, [PISSN 2086-9487] [E-ISSN 2579-650x] Vol.5, No.2: 99-107, 2018.

[2] Sultan, A.B. Muljono, and I.M.A. Nrartha, Visualisasi Pengasutan Motor Induksitiga Fasa Berbasis Programmable Logic Control, Dielektrika, [PISSN 2086-9487] [E-ISSN 2579-650X] Vol.4, No.1: 58-69, 2017.

[3] A. Widyatmoko, I.B.F. Citarsa, and I.N.W. Satiawan, Realisasi Teknik Pengereman Dinamik.(Dynamic Braking) Untuk Motor Induksi Tiga Fase Menggunakan Arduino Uno, Dielektrika, [P-ISSN 2086-9487] [EISSN 2579-650X] Vol.4, No.1: 31-38, 2017.

[4] A.H. Santoso, R.N. Hasanah, and H. Suyono, Pengaruh Tipe Belitan Terhadap Unjuk Kerja Motor Induksi satu fasa, EECCIS Vol. 12, No. 2, 2018.

[5] Z. Anthony, E. Erhaneli, Desain Lilitan Motor Induksi 1 Fasa dengan 4 Kumparan yang Tidak Identik Sama (Studi Kasus: Daya Keluaran dan Efisiensi Motor), EECCIS Vol. 12, No. 2, 2018.

[6] M. Putra, Z. Bahri, and M.F. Siregar, Penggunaan Transformator Arus Untuk Pencegahan Pemakaian Arus Ilegal, JESCE, p-ISSN: 2549-628X e-ISSN: 2549-6298, 2018.

[7] A.A.N. Amrita, W.G. Ariastina, and I.B.G. Manuaba, Study of Transformer Lifetime Due to Loading Process on $20 \mathrm{KV}$ Distribution Line, JEET, p-ISSN: 2549-8304 e-ISSN: 2622-0393, 2018.

[8] K.W. Widiatmika, I.W.A.Wijaya, and I.N. Setiawan, Analisis Penambahan Transformator Sisipan Untuk Mengatasi Overload Pada Transformator DB0244 di penyulang sebelanga, Spektrum, Volt. 5 No. 2, 2018.

[9] M.D. Noviantari, I.N. Suweden, and I.M. Mataram, Analisis Stabilitas Sistem Tenaga Listrik Dengan Automatic Generation Control (AGC) Dua Area Menggunakan Metode Fuzzy Logic Controller, MITE, p-ISSN: 1693-2951; e-ISSN: 2503-2372, Vol. 17, No. 2, 2018.

[10] I.G.A.T.K. Putra, I.W. Rinas, and Y.P. Sudarmojo, Analisis Pengaruh Pemasangan Dynamic Voltage Restorer (DVR) Terhadap Kedip Tegangan Akibat Gangguan Hubung Singkat 3 Fasa Pada Penyulang Kampus, MITE, p-ISSN: 1693-2951; e-ISSN: 2503-2372, Vol. 16, No. $03,2017$. 
\{ Halaman ini sengaja dikosongkan \} 